\title{
Fabrication of Inorganic/Organic Hybrid Heterojunctions of Polyaniline Composite/Blend for the Study of Diode Characteristics
}

\author{
Jyoti Manish Ghushe, ${ }^{1}$ Sushama Milind Giripunje ${ }^{2 *}$ and Subhash Baburao Kondawar ${ }^{3}$ \\ ${ }^{1}$ Department of Applied Physics, Priyadarshini College of Engineering, \\ Nagpur, Maharashtra 440018, India \\ ${ }^{2}$ Department of Applied Physics, Visvesvaraya National Institute of Technology, \\ Nagpur, Maharashtra 440010, India \\ ${ }^{3}$ Department of Physics, Rashtrasant Tukadoji Maharaj Nagpur University, \\ Nagpur, Maharashtra 440033, India
}

"Corresponding author: smgiripunje@phy.vnit.ac.in

Published online: 15 April 2017

To cite this article: Ghushe, J. M., Giripunje, S. M. \& Kondawar, S. B. (2017). Fabrication of inorganic/organic hybrid heterojunctions of polyaniline composite/blend for the study of diode characteristics. J. Phys. Sci., 28(1), 99-109, https://doi.org/10.21315/jps2017.28.1.8

To link to this article: https://doi.org/10.21315/jps2017.28.1.8

\begin{abstract}
Inorganic/organic hybrid heterojunctions of polyaniline composite/blend with metal doped zinc oxide nanorods (NRs) have been fabricated and systematically investigated for diode characteristics. Vertically aligned aluminium ( $\mathrm{Al}$ ) and iron ( $\mathrm{Fe}$ ) doped $\mathrm{ZnO}$ nanorods were grown on fluorine-doped tin oxide (FTO) coated glass slides using cost effective, eco-friendly and simple solution chemistry methods. Heterojunctions of doped $\mathrm{ZnO}$ NRs with polyaniline (PANI), poly(3,4-ethylenedioxythiophene) doped with poly(4styrenesulfonate) (PEDOT:PSS) and PANI:MWCNT nanocomposite and PANI:PEDOT:PSS blend showed rectifying behaviour with large rectification ratios. SEM results show clear interface between ZnO nanorods and PEDOT:PSS, PANI:MWCNT nanocomposite and PANI:PEDOT:PSS blend indicating junction formation. Ideality factors and barrier heights were calculated using thermionic emission model. Heterojunctions of undoped and doped ZnO NRs with PANI:MWCNT composite showed moderate ideality factors, reduced barrier heights and greater forward current as compared to heterojunctions of undoped and doped ZnO NRs with PANI:PEDOT:PSS blend. The study is innovative and important with respect to selection of materials for fabricating hybrid $p$ - $n$ heterojunction diodes.
\end{abstract}

Keywords: Inorganic/organic, nanocomposite, heterojunctions, ideality factor, blend 


\section{INTRODUCTION}

Vertically aligned zinc oxide ( $\mathrm{ZnO})$ nanorods (NRs), among other nanostructures of $\mathrm{ZnO}$, received considerable attention due to interesting structural and optoelectronic properties. $\mathrm{ZnO} \mathrm{NRs}$ provide large surface area to volume ratio, higher optical band gaps compared to that of $\mathrm{ZnO}$ nanoparticles and provide one dimensional conducting paths for electrons. They serve as transparent conducting oxides and have a potential to replace fluorine-doped tin oxide/indium tin oxide (FTO/ITO) substrates in photovoltaic applications. ${ }^{1-6}$ Huang et al. showed enhanced photocatalytic activity and high photostability under visible and UV light irradiation for $\mathrm{ZnO}$ nanorods prepared by one step pyrolytic synthesis route. ${ }^{7}$ $\mathrm{Al}$ and Fe doping enhances electrical and optical properties of $\mathrm{ZnO}$ NRs without deteriorating its wurtzite crystal structure and $\mathrm{n}$ type character. $\mathrm{Al}$ and $\mathrm{Fe}$-doped $\mathrm{ZnO}$ nanorods are of great potential in many applications due to the excellent electronic, magnetic, and optical properties..$^{8-15}$

$\mathrm{ZnO}$ /inorganic semiconductor heterojunction electronic devices like $\mathrm{ZnO} / \mathrm{p}-\mathrm{Si}$, $\mathrm{ZnO} / \mathrm{p}-\mathrm{NiO}$ and $\mathrm{ZnO} / \mathrm{p}-\mathrm{SiC}$ have been reported for various opto-electronic and photonic applications, but their synthesis methods are quite expensive. ${ }^{16-19}$ Caglar et al fabricated $\mathrm{p}-\mathrm{Si} / \mathrm{n}-\mathrm{ZnO}$ and $\mathrm{p}-\mathrm{Si} / \mathrm{n}$-FZN heterojunction diodes and investigated their electrical properties. The parameters like ideality factor (n), barrier height $\left(\varphi_{b}\right)$, and series resistance $\left(R_{s}\right)$ were calculated from the current-voltage (I-V) curves that exhibited rectifying behavior for these heterojunctions. ${ }^{20}$ Khan et al. studied junction properties of gold-zinc oxide nanorods-based Schottky diode by means of frequency dependent electrical characterisation on textile. ${ }^{21}$

On the other hand, $\mathrm{ZnO}$ /organic hybrid structure has emerged as a new competent candidate for solar cell, photodiode, photovoltaic and photochemical applications..$^{22,23}$ Talib et al. fabricated $\mathrm{ZnO}$ NRs/polyaniline $\mathrm{p}-\mathrm{n}$ junction photodetectors on flexible substrates. The $\mathrm{ZnO}$ NRs/PANI junction showed a high sensitivity of $85 \%$ whereas the photodetectors showed quantum efficiency as high as $12 \%{ }^{24}$

Conducting polymers polyaniline (PANI), polythiophene (PTh), poly(3,4ethylenedioxythiophene) doped with poly(4-styrenesulfonate) (PEDOT:PSS), PANI:multi-walled carbon nanotube (MWCNT) nanocomposites and PANI blends show p-type semiconducting nature and have been proposed for their use as hole transporting layers (HTL) or electrodes in organic solar cells and light emitting diodes. ${ }^{25-27}$

Inorganic materials offer wide range light absorption, effective charge carrier transport, highly crystalline nature, firmness, hardness and thermal stability. 
Organic conducting polymers have advantage of cost effective chemical synthesis methods, flexibility, easy chemical modification and solution processability. Hybrid structures thus can combine the properties of inorganic and organic materials for synergistic applications. A number of research papers on electrical and optical properties and various applications of $\mathrm{ZnO}$ NRs, polyaniline, PEDOT:PSS, PANI:MWCNT nanocomposites and PANI blends have been published over a decade, but less attention was given to the study of hybrid heterojunctions. A lot of work has been done on $\mathrm{ZnO} / \mathrm{PANI}$ and $\mathrm{ZnO}$ /PEDOT:PSS heterojunctions, but little attention is given to $\mathrm{Al}$ and $\mathrm{Fe}$ doped $\mathrm{ZnO}$ NRs for heterojunction applications. ${ }^{28-31}$

In this paper, we systematically investigated heterojunctions of different conducting polymers including PEDOT:PSS, PANI:MWCNT nanocomposite and PANI:PEDOT:PSS blend with ZnO NRs and $\mathrm{Al}$ and Fe doped $\mathrm{ZnO}$ NRs. The heterostructures find widespread opto-electronic applications.

\section{EXPERIMENTAL}

\subsection{Fabrication of Heterojunctions of Metal Doped $\mathrm{ZnO}$ NRs with PANI:MWCNT Nanocomposite, PEDOT:PSS and PANI:PEDOT:PSS(1:2) Blend}

Doped ZnO NRs were grown on seed ZnO layer on FTO glass by SILAR and HTCBD methods as reported in our earlier work. ${ }^{31}$ PANI:MWCNT nanocomposite was synthesised using in-situ chemical oxidative polymerisation methods $\mathrm{s}^{32,33}$ and dissolved in glycerol to form a gel. The gel was spin coated on $\mathrm{ZnO}$ NRs and $\mathrm{Al} / \mathrm{Fe}$ doped $\mathrm{ZnO} \mathrm{NRs}$ at the rate of $3000 \mathrm{rpm}$. PEDOT:PSS was dissolved in dimethyl sulphoxide (DMSO) and spin coated at a rate of $3000 \mathrm{rpm}$ on $\mathrm{ZnO}$ NRs and $\mathrm{Al} / \mathrm{Fe}$ doped $\mathrm{ZnO}$ NRs. PANI:PEDOT:PSS blend in DMSO was prepared by mixing PANI and PEDOT:PSS in the ratio 1:2. This blend solution was then spin coated on $\mathrm{ZnO} \mathrm{NRs}$ and $\mathrm{Al} / \mathrm{Fe}$ doped $\mathrm{ZnO}$ NRs to form heterojunctions. All the heterojunctions were annealed at $100^{\circ} \mathrm{C}$ and then thermally evaporated with silver (Ag) for making ohmic contacts. Schematic of an inorganic/organic hybrid $\mathrm{ZnO} /$ PANI:MWCNT nanocomposite heterojunction is shown in Scheme 1. 


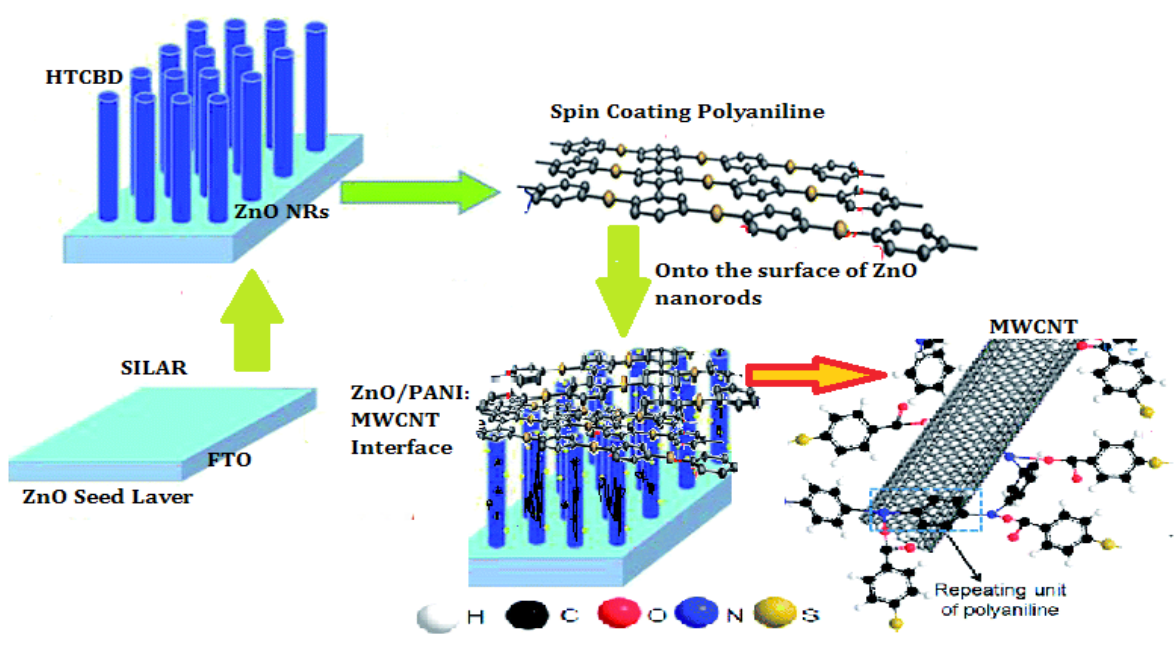

Scheme 1: Schematic of inorganic/organic hybrid heterojunction.

\subsection{Instrumentation}

The surface morphology of the heterojunctions was characterised by using JEOL 6380A scanning electron microscope. The electrical characterisation of all the heterojunctions was done using Keithley's 2611B source meter.

\section{RESULTS AND DISCUSSION}

Figure 1 shows SEM image of (a) ZnO/PEDOT:PSS heterojunction and (b) $\mathrm{ZnO} / \mathrm{PANI}$ :MWCNT nanocomposite heterojunction. It is observed from Figure (a) that PEDOT:PSS gets uniformly dispersed on the $\mathrm{ZnO}$ nanorods. Figure (b) shows vertically aligned $\mathrm{ZnO}$ nanorods and tubular coiled PANI:MWCNT nanocomposite on the top of the nanorods. The interface between the two is clearly seen in the SEM image. Figure 2 shows the SEM image of the cross sectional view of $\mathrm{ZnO}$ NRs/PANI:PEDOT:PSS(1:2) heterojunction. On the seed layer of ZnO about $500 \mathrm{~nm}$ thick, $\mathrm{ZnO}$ nanorods of diameter about 100-120 nm are grown, the length is about $1-2 \mu \mathrm{m}$. The blend layer (about $1 \mu \mathrm{m}$ thick)-metal oxide interface is seen in the cross sectional view of the SEM image. The ohmic contacts Ag layer is about $100 \mathrm{~nm}$ thick. 

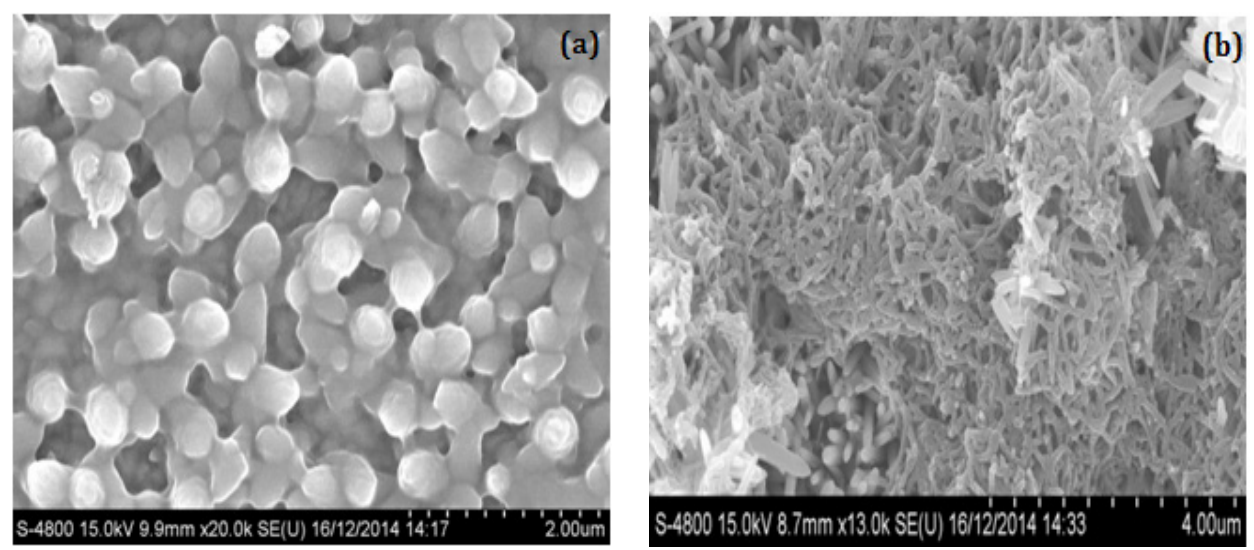

Figure 1: SEM image of (a) $\mathrm{ZnO} / \mathrm{PEDOT}$ : PSS heterojunction and (b) $\mathrm{ZnO} /$ PANI:MWCNT nanocomposite heterojunction.

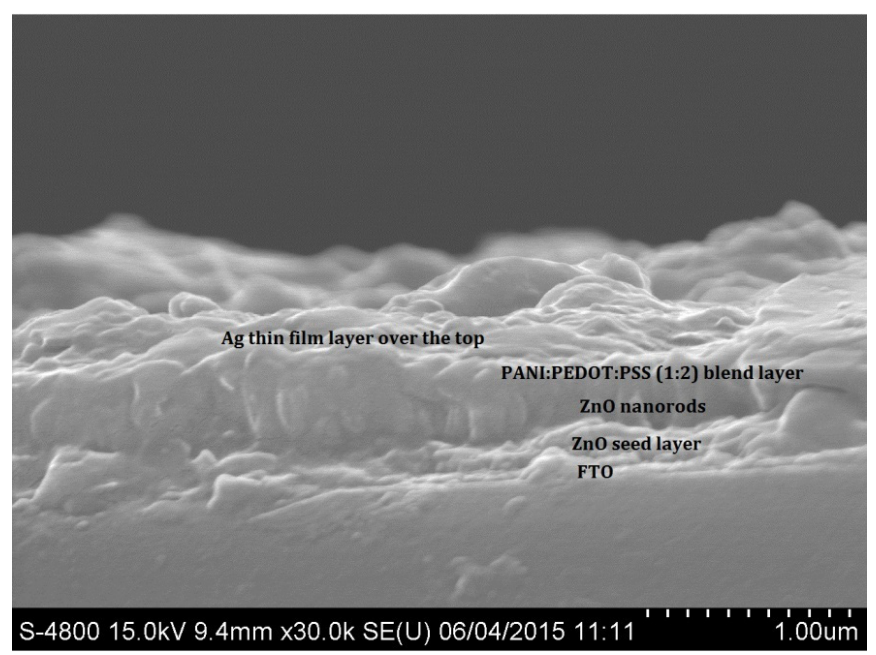

Figure 2: SEM image of the cross sectional view of $\mathrm{ZnO} / \mathrm{PANI}$ PEDOT:PSS(1:2) heterojunction.

Figure 3 is the electrical characteristics of (A) heterojunctions of PEDOT:PSS with (a) $\mathrm{ZnO}$, (b) $\mathrm{AlZnO}$ and (c) FeZnO; (B) heterojunctions of PANI:MWCNT nanocomposite with (a) $\mathrm{ZnO}$, (b) $\mathrm{AlZnO}$ and (c) $\mathrm{FeZnO}$; and (C) heterojunctions of PANI:PEDOT:PSS blend with (a) ZnO, (b) AlZnO and (c) FeZnO. All the heterojunctions show diode-like rectifying behaviours with the ratio of forward current to reverse current (rectification ratio) of the order of $10^{3}$. At the interface, due to carrier mismatch, a large diffusion of charge carriers (holes from $\mathrm{p}$ type polymer nanocomposite/blend and electrons from $\mathrm{n}$ type doped $\mathrm{ZnO} \mathrm{NRs}$ ) takes place during junction formation. The depletion region is formed which restricts 
further diffusion of the carriers. The energy levels rearrange in order to equalise the Fermi level, indicating junction formation. The interfaces of heterojunctions are not smooth and may result in potential wells at the junction which may lead to the trapping of electrons during forward or reverse biasing. The diode parameters were calculated using thermionic emission model and shown in Table 1. The Y-intercept of the graph of $\mathrm{Ln} \mathrm{I}_{\mathrm{s}}$ versus $\mathrm{V}$ gives barrier height whereas slope of the graph gives ideality factor of the diode.

In all the heterojunctions, the effect of doping in $\mathrm{ZnO}$ NRs by aluminium and iron has resulted in decrease in the cut-in voltages, which is indicative of increase in charge carrier concentrations in the doped ZnO NRs. The PANI:MWCNT nanocomposite heterojunction resulted in the highest forward currents of the order of several amperes, which is indicative of the synergistic effect of using MWCNTs as fillers to polyaniline. MWCNTs facilitate the charge transfer at the interface between the two thereby resulting in lowest barrier heights as compared to the other heterojunctions. The barrier height was found to be the lowest value 0.218 eV for ZnO/PANI:MWCNT heterojunction.

Figure 4 shows the ideality factors for various heterojunctions of conducting polymers with (a) $\mathrm{AlZnO}$, (b) FeZnO and (c) $\mathrm{ZnO}$. Among all the heterojunctions, ZnO/PANI:PEDOT:PSS showed the least ideality factor 1.569 closer to 1 compared to all other heterojunctions. The blend of PANI with PEDOT:PSS enhances the junction properties and better matching with wurtzite $\mathrm{ZnO}$ nanorods in the pure form compared to that of the doped form. The ideality factor is a size dependent electrical parameter as observed from its lowest value for $\mathrm{ZnO} / \mathrm{PANI}$ :PEDOT:PSS heterojunction. The interface of PANI:PEDOT:PSS(1:2) and ZnO NRs (diameter about $100-120 \mathrm{~nm}$ ) thus results in better structure matching as compared to $\mathrm{AlZnO}$ NRs (diameters about 80-90 nm) and FeZnO NRs (diameters about 20-30 nm). ${ }^{31}$ On the other hand, ZnO/PANI:PEDOT:PSS heterojunction exhibited larger value of barrier height $(0.547 \mathrm{eV})$ and hence larger turn on voltage as compared to that of other heterojunctions. 

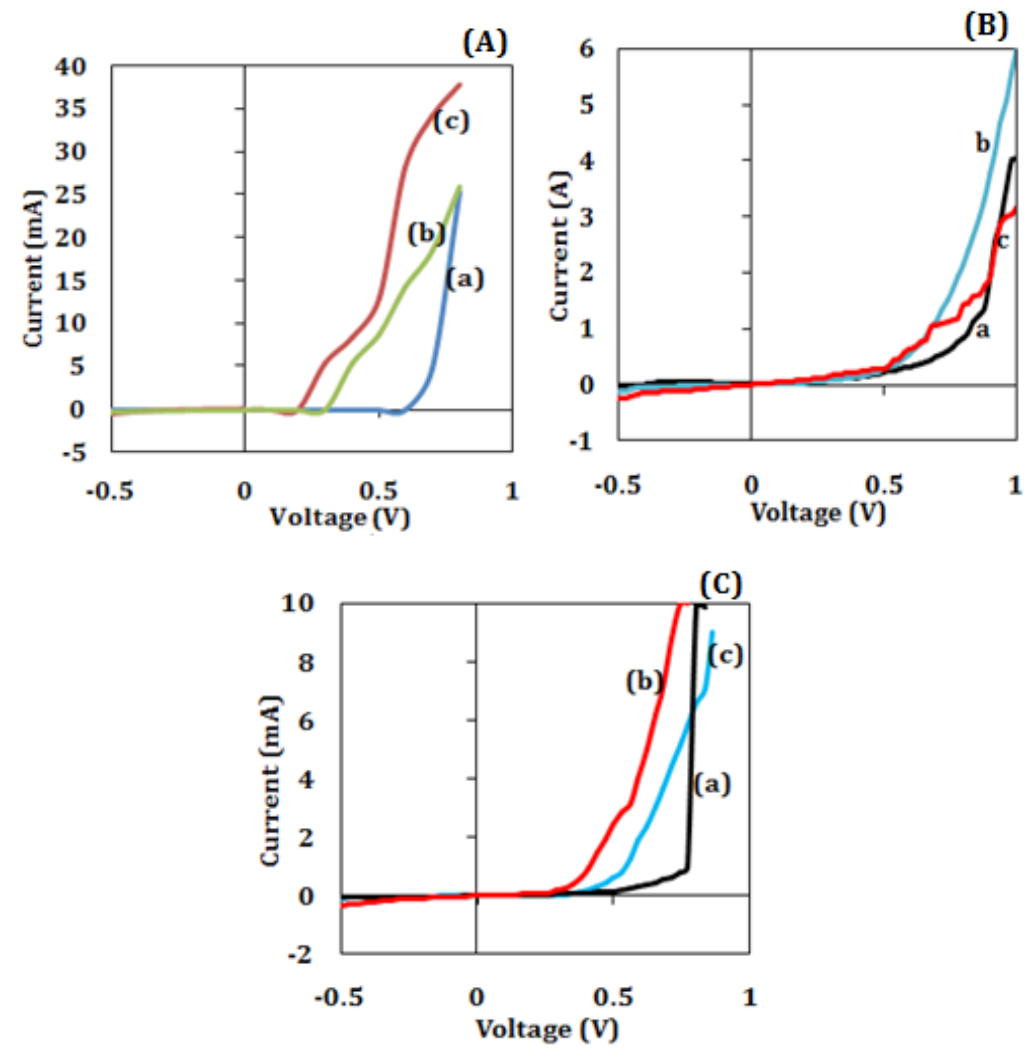

Figure 3: Electrical characteristics of (A) heterojunctions of PEDOT:PSS with (a) $\mathrm{ZnO}$, (b) AlZnO and (c) FeZnO; (B) heterojunctions of PANI:MWCNT nanocomposite with (a) $\mathrm{ZnO}$, (b) $\mathrm{AlZnO}$ and (c) $\mathrm{FeZnO}$; and (C) heterojunctions of PANI:PEDOT:PSS blend with (a) ZnO, (b) AlZnO and (c) FeZnO.

Ideality Factors for various heterojunctions
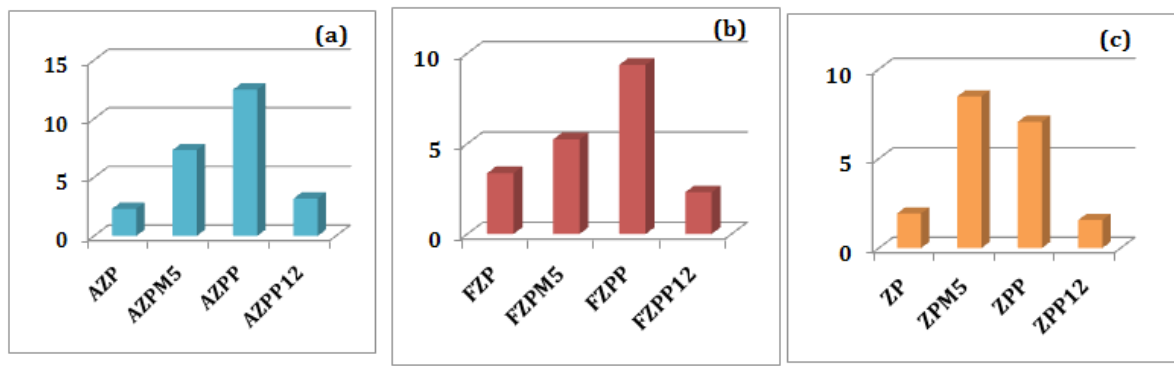

Figure 4: Ideality factors for various heterojunctions of conducting polymers with (a) $\mathrm{AlZnO}$, (b) FeZnO and (c) $\mathrm{ZnO}$. 
Table 1: Estimation of Diode parameters for various inorganic/organic hybrid heterojunctions

\begin{tabular}{lllll}
\hline Heterojunction & $\begin{array}{l}\text { Sample } \\
\text { name }\end{array}$ & $\begin{array}{l}\text { Ideality } \\
\text { factor }(\eta)\end{array}$ & $\begin{array}{l}\text { barrier height } \\
\left(\Phi_{\mathrm{b}}\right) \mathrm{eV}\end{array}$ & $\begin{array}{l}\text { Reverse } \\
\text { saturation } \\
\text { current } \mathrm{I}_{\mathrm{s}}\end{array}$ \\
\hline ZnO/PANI $^{31}$ & ZP & 1.93 & 0.786 & $0.246 \mu \mathrm{A}$ \\
AlZnO/PANI $^{31}$ & AZP & 2.32 & 0.781 & $0.298 \mu \mathrm{A}$ \\
FeZnO/PANI $^{31}$ & FZP & 3.367 & 0.670 & $21 \mu \mathrm{A}$ \\
ZnO/PANI:MWCNT & ZPM5 & 8.48 & 0.218 & $0.109 \mu \mathrm{A}$ \\
AlZnO/PANI:MWCNT & AZPM5 & 7.33 & 0.26 & $0.187 \mu \mathrm{A}$ \\
FeZnO/PANI:MWCNT & FZPM5 & 5.236 & 0.338 & $8.05 \mathrm{~mA}$ \\
ZnO/PEDOT:PSS & ZPP & 7.06 & 0.398 & $0.735 \mathrm{~mA}$ \\
AlZnO/PEDOT:PSS & AZPP & 12.49 & 0.368 & $2.370 \mathrm{~mA}$ \\
FeZnO/PEDOT:PSS & FZPP & 9.36 & 0.389 & $1.064 \mathrm{~mA}$ \\
ZnO/PANI:PEDOT:PSS(1:2) & ZPP12 & 1.569 & 0.547 & $0.0024 \mathrm{~mA}$ \\
AlZnO/ & AZPP12 & 3.195 & 0.493 & $0.0189 \mathrm{~mA}$ \\
PANI:PEDOT:PSS(1:2) & & & & $0.0099 \mathrm{~mA}$ \\
FeZnO/ & FZPP12 & 2.309 & 0.510 & \\
PANI:PEDOT:PSS(1:2) & & & &
\end{tabular}

\section{CONCLUSION}

SEM results show clear interface between $\mathrm{ZnO}$ nanorods and PEDOT:PSS, PANI:MWCNT nanocomposite and PANI:PEDOT:PSS blend indicating junction formation. Heterojunctions of undoped and doped ZnO NRs with PANI:MWCNT composite showed moderate ideality factors, reduced barrier heights and greater forward current as compared to heterojunctions of undoped and doped $\mathrm{ZnO} \mathrm{NRs}$ with PANI:PEDOT:PSS blend. Blend or composite based heterojunctions are very useful in designing superior diodes where rapid change in the value of currents with respect to some physical quantity is required.

\section{ACKNOWLEDGEMENTS}

Author Sushma M. Giripunje acknowledges the Department of Science and Technology (DST) India for providing financial support to carry out the research work through a SERB funded project grant no. EMR/2015/001711. 


\section{REFERENCES}

1. Dulub, O., Boatner, L. \& Diebold, U. (2002). STM study of the geometric and electronic structure of $\mathrm{ZnO}(0001)-\mathrm{Zn},(000 \overline{1})-\mathrm{O},(10 \overline{1} 0)$, and (11 $\overline{2} 0)$ surfaces. Appl. Surf. Sci., 519(3), 201-217, https://doi.org/10.1016/S00396028(02)02211-2.

2. Meyer, B. \& Marx, D. (2003). Density-functional study of the structure and stability of ZnO surfaces. Phys. Rev. B., 67, 035403 https://doi.org/10.1103/ physrevb.67.035403.

3. Look, D. \& Claflin, B. (2004). P-type doping and devices based on $\mathrm{ZnO}$. Phys. Stat. Sol. B, 241, 624-630, https://doi.org/10.1002/pssb.200304271.

4. $\mathrm{Ku}, \mathrm{C} . \& \mathrm{Wu}, \mathrm{J}$. (2007). Electron transport properties in $\mathrm{ZnO}$ nanowire array/nanoparticle composite dye-sensitized solar cells. Appl. Phys. Lett., 91, 093117-3, https://doi.org/10.1063/1.2778454.

5. Samuel, S., Bose, L. \& George, K. (2009). Optical properties of ZnO nanoparticle. SB Acad. Rev., 11(1 \& 2), 57-65.

6. Virendra, P. et al. (2006). Spectroscopic characterization of zinc oxide nanorods synthesized by solid-state reaction. Spectrochim. Acta A, 65, 173178, https://doi.org/10.1016/j.saa.2005.10.001.

7. Huang, N. et al. (2015). One-step pyrolytic synthesis of $\mathrm{ZnO}$ nanorods with enhanced photocatalytic activity and high photostability under visible light and UV light irradiation. J. Alloys Comp., 648, 919-929, https://doi. org/10.1016/j.jallcom.2015.07.039.

8. Ramgir, N., Yang, Y. \& Zacharias, M. (2010). Nanowire-based sensors. Small, 6(16), 1705-1722, https://doi.org/10.1002/smll.201000972.

9. Venkatachalapathy, V. et al. (2011). Tuning light absorption by band gap engineering in $\mathrm{ZnCdO}$ as a function of MOVPE-synthesis conditions and annealing. J. Cryst. Gr., 315, 301-304, https://doi.org/10.1016/j. jcrysgro.2010.09.056.

10. Cheng, C. et al. (2008). Hydrothermal synthesis Ni-doped $\mathrm{ZnO}$ nanorods with room-temperature ferromagnetism. Mater. Lett., 62, 1617-1620, https:// doi.org/10.1016/j.matlet.2007.09.035.

11. Ghosh, A., Karak, N. \& Kundu, T. (2013). Effect of Co doping on optical behaviors in $\mathrm{ZnO}$ nanorods. AIP Conf. Proc., 1536, 177-178, https://doi. org/10.1063/1.4810158.

12. Zhou, H. et al. (2007). Preparation of aluminum doped zinc oxide films and the study of their microstructure, electrical and optical properties. Thin Solid Films, 515, 6909-6914, https://doi.org/10.1016/j.tsf.2007.01.041. 
13. Salaken, S., Farzana, E. \& Podder, J. (2013). Effect of Fe-doping on the structural and optical properties of $\mathrm{ZnO}$ thin films prepared by spray pyrolysis. J. Semicond., 34(7), 073003-1-6, https://doi.org/10.1088/16744926/34/7/073003.

14. Xu, L. \& Li, X. (2010). Influence of Fe-doping on the structural and optical properties of $\mathrm{ZnO}$ thin films prepared by sol-gel method. J. Crys. Gr., 312, 851-855, https://doi.org/10.1016/j.jcrysgro.2009.12.062.

15. Liu, L. et al. (2016). Effects of intermittent atomization on the properties of Al-doped $\mathrm{ZnO}$ thin films deposited by aerosol-assisted chemical vapor deposition. Thin Solid Films, 605, 163-168, https://doi.org/10.1016/j. tsf.2015.09.011.

16. Mridha, S. \& Basak, D. (2007). Ultraviolet and visible photoresponse properties of $n-\mathrm{ZnO} / p$-Si heterojunction. J. Appl. Phys,. 101, 1-5, https:// doi.org/10.1063/1.2724808.

17. Alivov, Y. I. et al. (2005). Photoresponse of $\mathrm{n}-\mathrm{ZnO} / \mathrm{p}-\mathrm{SiC}$ heterojunction diodes grown by plasma assisted molecular-beam epitaxy. Appl. Phys. Lett., 86, 1-3, https://doi.org/10.1063/1.1949730.

18. Jeong, I. S., Kim, J. H. \& Im, S. (2003). Ultraviolet-enhanced photodiode employing n-ZnO/p-Si structure. Appl. Phys. Lett., 83, 2946-2948, https:// doi.org/10.1063/1.1616663.

19. Vygraninko, Y., Wang, K. \& Nathan, A. (2006). Low leakage $p-\mathrm{NiO} / i-\mathrm{ZnO} / n-$ ITO heterostructure ultraviolet sensor. Appl. Phys. Lett., 89, 172105, https:// doi.org/10.1063/1.2364269.

20. Ilican, S. et al. (2016). XPS Studies of electrodeposited grown F-doped ZnO rods and electrical properties of p-Si/n-FZN heterojunctions. J. Nanomater, Article ID 6729032, https://doi.org/10.1155/2016/6729032.

21. Khan, A. et al. (2014). Analysis of junction properties of gold-zinc oxide nanorods-based Schottky diode by means of frequency dependent electrical characterization on textile. J. Mater. Sci., 49(9), 3434-3441, https://doi. org/10.1007/s10853-014-8053-2.

22. Peiro A. M. et al. (2006). Hybrid polymer/metal oxide solar cells based on $\mathrm{ZnO}$ columnar structures. J. Mater. Chem., 16, 2088-2096, https://doi. org/10.1039/b602084d.

23. Liu, J. P. et al. (2007). Fabrication of $\mathrm{ZnO}$ and its enhancement of charge injection and transport in hybrid organic/inorganic light emitting devices. Appl. Surf. Sci., 253, 7506-7509, https://doi.org/10.1016/j. apsusc.2007.03.043.

24. Talib, R. et al. (2016) $\mathrm{ZnO}$ nanorods/polyaniline heterojunctions for lowpower flexible light sensors. Mat. Chem. Phys. 181, 7-11, https://doi. org/10.1016/j.matchemphys.2016.06.061. 
25. Saikia, P. J. \& Sarmah, P. C. (2011). Investigation of polyaniline thin film and schottky junction with aluminium for electrical and optical characterization. Mater. Sci. Appl., 2, 1022-1026, https://doi.org/10.4236/msa.2011.28138.

26. Sharma A. K. et al. (2012). Solvent tuned PANI-CNT composites as advanced electrode materials for supercapacitor application. Adv. Mat. Lett., 3(2), 82-86, https://doi.org/10.5185/amlett.2012.1315.

27. Moreno, J. R. et al. (2012). Semitransparent ZnO/poly(3,4ethylenedioxythiophene) based hybrid inorganic/organic heterojunction thin film diodes prepared by combined radio-frequency magnetron-sputtering and electrodeposition techniques. Thin Solid Films, 525, 88-92, https://doi. org/10.1016/j.tsf.2012.10.067.

28. Sharma, B., Banothu, B. \& Khare, N. (2011). Polyaniline/ZnO heterojunction, AIP Conf. Proc., 1349, 713-714, https://doi.org/10.1063/1.3606057.

29. Tang, Q. et al. (2012). p-n Heterojunction on ordered $\mathrm{ZnO}$ nanowires/ polyaniline microrods double array. Langmuir, 28(8), 3972-3978, https:// doi.org/10.1021/la204522v.

30. Sharma, B. \& Khare, N. (2013). Effect of UV exposure on rectifying behavior of polyaniline/ZnO heterojunction. Semicond. Sci. Tech., 28(12), 125022, https://doi.org/10.1088/0268-1242/28/12/125022.

31. Ghushe, J., Giripunje, S. \& Kondawar, S. (2016). Effect of metal doped zinc oxide nanorods on photoelectrical characteristics of $\mathrm{ZnO} /$ polyaniline heterojunction. J. Inorg. Organo. Mett. Polym. Mater., 26(2), 370-375, https://doi.org/10.1007/s10904-016-0333-7.

32. Sharma, A. K. \& Sharma, Y. (2013). p-toluene sulfonic acid doped polyaniline carbon nanotube composites: Synthesis via different routes and modified properties. J. Electrochem. Sci. Eng., 3(2), 47-56, https://doi.org/10.5599/ jese.2013.0029.

33. Kar, P. \& Chodhaury, A. (2013). Carboxylic acid functionalized multiwalled carbon nanotube doped polyaniline for chloroform sensors. Sensors Actuators B, 183, 25-33, https://doi.org/10.1016/j.snb.2013.03.093. 